\title{
Impact of poor mental health in adult spinal deformity patients with poor physical function: a retrospective analysis with a 2-year follow-up
}

\author{
Joshua Bakhsheshian, MD, ${ }^{1}$ Justin K. Scheer, BS, ${ }^{2}$ Jeffrey L. Gum, MD, ${ }^{3}$ Richard Hostin, MD, ${ }^{4}$ \\ Virginie Lafage, PhD, ${ }^{5}$ Shay Bess, MD, ${ }^{6}$ Themistocles S. Protopsaltis, MD, ${ }^{5}$ \\ Douglas C. Burton, MD, ${ }^{7}$ Malla Kate Keefe, BS, ${ }^{8}$ Robert A. Hart, MD, ${ }^{9}$ Gregory M. Mundis Jr., MD, ${ }^{10}$ \\ Christopher I. Shaffrey, MD, ${ }^{11}$ Frank Schwab, MD, ${ }^{5}$ Justin S. Smith, MD, PhD,11 \\ Christopher P. Ames, MD, ${ }^{8}$ and the International Spine Study Group
}

\begin{abstract}
${ }^{1}$ Department of Neurological Surgery, Keck School of Medicine, University of Southern California, Los Angeles; ${ }^{2}$ University of California, San Diego, School of Medicine; ${ }^{10}$ Scripps Health, La Jolla; ${ }^{8}$ Department of Neurological Surgery, University of California, San Francisco, California; ${ }^{3}$ Norton Leatherman Spine Center, Louisville, Kentucky; ${ }^{4}$ Department of Orthopaedic Surgery, Baylor Scoliosis Center, Plano, Texas; ${ }^{5}$ Department of Orthopaedic Surgery, NYU Hospital for Joint Diseases, New York, New York; ${ }^{6}$ Rocky Mountain Hospital for Children, Denver, Colorado; ${ }^{7}$ Department of Orthopaedic Surgery, University of Kansas Medical Center, Kansas City, Kansas; ' Department of Orthopaedic Surgery, Oregon Health \& Science University, Portland, Oregon; and ${ }^{11}$ Department of Neurosurgery, University of Virginia Health System, Charlottesville, Virginia
\end{abstract}

OBJECTIVE Mental disease burden can have a significant impact on levels of disability and health-related quality of life (HRQOL) measures. Therefore, the authors investigated the significance of mental health status in adults with spinal deformity and poor physical function.

METHODS A retrospective analysis of a prospective multicenter database of 365 adult spinal deformity (ASD) patients who had undergone surgical treatment was performed. Health-related QOL variables were examined preoperatively and at the 2-year postoperative follow-up. Patients were grouped by their 36-Item Short Form Health Survey mental component summary (MCS) and physical component summary (PCS) scores. Both groups had PCS scores $\leq 25$ th percentile for matched norms; however, the low mental health $(\mathrm{LMH})$ group consisted of patients with an MCS score $\leq 25$ th percentile, and the high mental health $(\mathrm{HMH})$ group included patients with an MCS score $\geq 75$ th percentile.

RESULTS Of the 264 patients (72.3\%) with a 2-year follow-up, 104 (28.5\%) met the inclusion criteria for LMH and 40 patients $(11.0 \%)$ met those for HMH. The LMH group had a significantly higher overall rate of comorbidities, specifically leg weakness, depression, hypertension, and self-reported neurological and psychiatric disease processes, and were more likely to be unemployed as compared with the HMH group ( $p<0.05$ for all). The 2 groups had similar 2-year postoperative improvements in HRQOL ( $p>0.05$ ) except for the greater improvements in the MCS and the Scoliosis Research Society-22r questionnaire (SRS-22r) mental domain $(p<0.05)$ in the LMH group and greater improvements in PCS and SRS-22r satisfaction and back pain domains $(p<0.05)$ in the HMH group. The LMH group had a higher rate of reaching a minimal clinically important difference (MCID) on the SRS-22r mental domain ( $p<0.01)$, and the HMH group had a higher rate of reaching an MCID on the PCS and SRS-22r activity domain $(p<0.05)$. On multivariable logistic regression, having LMH was a significant independent predictor of failure to reach an MCID on the PCS $(p<0.05)$. At the 2-year postoperative follow-up, $14 \mathrm{LMH}$ patients (15.1\%) were categorized as HMH. Two LMH patients (2.2\%), and 3 $\mathrm{HMH}$ patients $(7.7 \%)$ transitioned to a PCS score $\geq 75$ th percentile for age- and sex-matched US norms $(p<0.01)$.

\footnotetext{
ABBREVIATIONS ASA = American Society of Anesthesiologists; ASD = adult spinal deformity; BMI = body mass index; DRAM = Distress and Risk Assessment Method; $\mathrm{EBL}=$ estimated blood loss; HMH = high mental health; HRQOL = health-related quality of life; LL = lumbar lordosis; LMH = low mental health; LOS = length of hospital stay; $\mathrm{MCID}=$ minimal clinically important difference; $\mathrm{MCS}$ = mental component summary; NRS = numeric rating scale; ODI = Oswestry Disability Index; PCS = physical component summary; PI = pelvic incidence; PT = pelvic tilt; SF-36 = 36-Item Short Form Health Survey; SRS-22r = Scoliosis Research Society-22r questionnaire; SVA = sagittal vertical axis; TK = thoracic kyphosis.
} SUBMITTED December 8, 2015. ACCEPTED May 13, 2016.

INCLUDE WHEN CITING Published online August 19, 2016; DOI: 10.3171/2016.5.SPINE151428. 


\begin{abstract}
CONCLUSIONS While patients with poor mental and physical health, according to their MCS and PCS scores, have higher medical comorbidity and unemployment rates, they still demonstrate significant improvements in HRQOL measurements postoperatively. Both $\mathrm{LMH}$ and $\mathrm{HMH}$ patient groups demonstrated similar improvements in most $\mathrm{HRQOL}$ domains, except that the LMH patients had difficulties in obtaining improvements in the PCS domain.
\end{abstract}

http://thejns.org/doi/abs/10.3171/2016.5.SPINE151428

KEY WORDS adult spinal deformity; health-related quality of life; HRQOL; outcomes; sagittal alignment; sagittal vertical axis; mental health

I $\mathrm{T}$ is well known that deformity of the spine has a significant impact on the health-related quality of life (HRQOL) of adults; ${ }^{2,17}$ however, the impact of the mental health burden in patients with adult spinal deformity (ASD) treated with surgical spinal reconstruction is less clear. Although screening for a history of mental health disease has been advocated in the preoperative planning for reconstructive spine surgery, ${ }^{14}$ a survey completed by 110 spine surgeons from the US revealed that only $37 \%$ routinely use some form of mental health screening. ${ }^{28}$ It can be difficult to assess if mental distress is reactive, directly related to the anatomical pathology requiring surgery, or an inherent disorder requiring psychosocial treatments. $8,10,23$

Preoperative mental disease burden has been reported to have a significant impact on levels of pain intensity, disability, and HRQOL measures in patients undergoing spine surgery (Bakhsheshian et al., unpublished data, 2016). ${ }^{1,9}$, 10,13,23 Preoperative psychiatric conditions have been shown to be an independent risk factor for the development of adverse events during hospitalization after spine surgery. ${ }^{15}$ However, other investigations have failed to demonstrate an association between self-reported psychological conditions and outcome scores following lumbar spine surgery. ${ }^{1,13}$ Of note, these studies did not have predefined comparative study groups, meaning that they did not classify patients with significant functional impairment as scoring at or below the 25 th percentile for age- and sex-matched US population norms. ${ }^{20}$ Further, the minimal clinically important differences (MCIDs) were not evaluated.

To date, there is a paucity of information on the impact of severe mental health disease in ASD patients undergoing reconstructive spine surgery. Patients with ASD increasingly expect treatments that allow them to stay active, and spine surgeons are asked to evaluate patients with mental health parameters that could confound the predicted surgical prognosis. Greater information on the impact of mental health parameters can help the patient and surgeon decide on the most appropriate treatment approach. Thus, in the following study, we assessed the impact of poor mental health on ASD patients with poor physical function using the hypothesis that patients with poor mental health preoperatively may have worse 2 -year outcomes than those with good preoperative mental health.

\section{Methods \\ Patient Population}

We retrospectively reviewed a prospective ASD data- base covering 11 different sites in the US. The database undergoes periodic quality-control checks and is verified by independent reviewers. All sites enrolled patients with an institutional review board-approved protocol. Criteria for inclusion into the database were a patient age $\geq 18$ years and spinal deformity as defined by the presence of at least one of the following: coronal Cobb angle $\geq 20^{\circ}$, sagittal vertical axis $(\mathrm{SVA}) \geq 5 \mathrm{~cm}$, pelvic tilt $(\mathrm{PT}) \geq 25^{\circ}$, and/or thoracic kyphosis $(\mathrm{TK}) \geq 60^{\circ}$. Exclusion criteria included the presence of a neuromuscular etiology or an active infection or malignancy.

The 36-Item Short Form Health Survey (SF-36) questionnaire was designed for a general self-reported health assessment and entails the physical component summary (PCS) and mental component summary (MCS) scores. ${ }^{22}$ Two patient groups were identified using as the cutoff point scoring in either the lower 25th percentile or the top 25 th percentile for age- and sex-matched US norms. ${ }^{20,27}$ This was done to identify the ratio of the extreme portion of preoperative patients with low PCS scores ( $\leq 25$ th percentile) and low MCS scores $(\leq 25$ th percentile) or high MCS scores $(\geq$ 75 th percentile). Therefore, the 2 comparison groups consisted of the following: low mental health (LMH) group, PCS scores $\leq 25$ th percentile and MCS scores $\leq 25$ th percentile; and high mental health (HMH) group, PCS scores $\leq 25$ th percentile and MCS scores $\geq 75$ th percentile.

\section{Demographics and HRQOL Measurements}

The demographic data included age, sex, body mass index (BMI), Charlson Comorbidity Index, ${ }^{6}$ individual comorbidities, and work status. The surgical data included the American Society of Anesthesiologists (ASA) physical status classification, length of hospital stay (LOS), operating room time, estimated blood loss (EBL), and number of patients that had at least one direct decompression. Standardized HRQOL measures included the Oswestry Disability Index (ODI), SF-36, and Scoliosis Research Society-22r questionnaire (SRS-22r). The SRS-22r provides multiple subdomains (activity, pain, self-image, mental health, and satisfaction with management) and a total score. A numeric rating scale (NRS) score ranging from 0 (no pain) to 10 (worst pain) was individually collected for back and leg pain. Minimal clinically important difference values have been established for HRQOL measurements. ${ }^{3,7}$ To analyze clinically relevant changes, differences in the proportions of patients reaching the MCID for each HRQOL measure were also evaluated. The MCID values used in the present study included ODI -15 , PCS +5.2 , back and leg pain NRS -2 , SRS-22r activity +0.375 , 
SRS-22r pain +0.587 , SRS-22r self-image +0.8 , and SRS22r mental health $+0.42 .3,4,7$

\section{Radiographic Assessment}

All radiographic measures were performed at a central location using standardized techniques. ${ }^{16}$ Standing lateral spine radiographs (36-inch cassette) at baseline and the 2-year follow-up were analyzed using validated software (Spineview, ENSAM, Laboratory of Biomechanics)..$^{5,19}$ Analyzed measurements included coronal Cobb angles of thoracic and lumbar curves, TK (T2-12, Cobb angle between the superior endplate of T-2 and the inferior endplate of T-12), lumbar lordosis (LL; Cobb angle between the superior endplate of L-1 and the superior endplate of S-1), SVA (C-7 plumbline relative to S-1), PT (angle formed by a line drawn from the midpoint of the sacral endplate to the center of the bicoxofemoral axis and a vertical plumbline extended from the bicoxofemoral axis), pelvic incidence (PI; angle formed by a line drawn between the center of the femoral head and the sacral endplate and a line drawn perpendicular to the center of the sacral endplate), and PILL mismatch (difference between LL and PI).

Patients were also stratified according to the SRSSchwab ASD classification for coronal curve locations. ${ }^{21}$ The coronal curve type is based on the maximal coronal angle measured while using the standard Cobb technique. The 4 curve types include Type T, a thoracic major curve $>30^{\circ}$ (apical level of T-9 or higher); Type L, a lumbar or thoracolumbar major curve $>30^{\circ}$ (apical level of T-10 or lower); Type $\mathrm{D}$, a double major curve (one $\mathrm{T}$ and one $\mathrm{L}$ curve) with each curve $>30^{\circ}$; and Type N, no coronal curve $>30^{\circ}$ (that is, no major coronal deformity).

\section{Statistical Analyses}

Continuous variables were described with the mean and standard deviation. Normality of data was determined using the Shapiro-Wilk test. Comparisons of means between the groups included pairwise comparisons using Tukey's honestly significant difference test to control for Type I error or Wilcoxon rank-sum test where appropriate. Frequency analyses for meeting the MCID and for the proportions of comorbidities between the groups were conducted via Pearson's $\chi^{2}$ analysis. Preliminary analysis suggested a higher prevalence of sagittal malalignment in the LMH group than in the HMH group. To ascertain the impact of $\mathrm{LMH}$ on outcomes independent of greater sagittal malalignment, multivariable binary logistic regression models were constructed for rates of meeting the MCID for each of the HRQOL measures with the following covariates controlled in the models: $\mathrm{LMH} / \mathrm{HMH}$ status (HMH as the reference), baseline age, sex, BMI, Charlson Comorbidity Index, baseline maximum coronal Cobb angle, PT, PI-LL, SVA, and preoperative HRQOL for the outcome (that is, preoperative ODI for the ODI MCID model). All statistical analyses were conducted using commercially available software (SPSS version 22, IBM Corp.), and the level of significance was set at $\mathrm{p}<0.05$ for all tests.

\section{Reporting Guidelines}

This article adheres to the reporting guideline of
Strengthening the Reporting of Observational Studies in Epidemiology (STROBE). ${ }^{25}$

\section{Results}

\section{Patient Selection}

Of the 365 patients in the database, 264 (72.3\%) were followed up for 2 years and 101 (27.7\%) were lost to follow-up (Fig. 1). One hundred forty-four patients (39.4\%) met the inclusion criteria for LMH (PCS scores $\leq 25$ th percentile and MCS scores $\leq 25$ th percentile for age- and sex-matched US population norms) or HMH (PCS scores $\leq 25$ th percentile and MCS scores $\geq 75$ th percentile for age- and sex-matched US population norms). The LMH group consisted of 104 patients (28.5\%) and the $\mathrm{HMH}$ group consisted of 40 patients $(11.0 \%)$.

\section{Preoperative Baseline Characteristics}

Both groups had similar preoperative characteristics except that the LMH group had a significantly higher BMI (Table 1). The LMH group also had a significantly higher rate of comorbidities ( $\mathrm{p}<0.05$; Table 2 ). When specific self-reported comorbidities were examined, the LMH group had a significantly higher rate of leg weakness, depression, hypertension, neurological disease, and psychiatric disease $(\mathrm{p}<0.05)$. The reported duration of symptoms with respect to spine problems or back pain was similar between the 2 groups; however, patients in the HMH group reported a slightly longer period of leg pain ( $p$ $<0.05$ ). More LMH patients were disabled, unemployed, or retired due to back pain $(\mathrm{p}<0.05)$. Both groups had similar coronal Cobb angles; however, the LMH group had significantly larger values for PI-LL and SVA $(\mathrm{p}<0.05$; Table 3). The LMH group had worse baseline HRQOL for all measures $(\mathrm{p}<0.05)$ except for PCS, baseline SRS-22r satisfaction, and back and leg pain NRS (Table 4).

\section{Two-Year Postoperative Outcomes}

As regards surgical data, the 2 groups had similar LOS, EBL, and number of patients undergoing a direct decompression (Table 1), although the ASA physical status was significantly worse in the LMH group $(\mathrm{p}<0.01)$. At 2 years postoperatively, the 2 groups demonstrated significant improvements compared with baseline PI-LL, SVA, and PT $(\mathrm{p}<0.01)$, and these changes were similar between the groups ( $p>0.05$; Table 3$)$. Both groups demonstrated significant improvements in all coronal Cobb angle measurements $(\mathrm{p}<0.05$ for all).

Both groups demonstrated significant improvements in all HRQOL measurements compared with baseline, except that the HMH group did not improve in the SRS-22r mental health score and showed significant worsening on the MCS (Table 4). When 2-year differences were compared between the groups, the HMH group demonstrated a greater increase in the PCS and a greater reduction in back pain $(\mathrm{p}<0.01)$, whereas the LMH group demonstrated greater improvements in the MCS, SRS-22r mental, and SRS-22r satisfaction. Furthermore, the LMH group had a higher rate of reaching SRS-22r mental MCID ( $p<$ 0.01 ), and the HMH group had a higher rate of reaching PCS and SRS-22r activity MCID ( $p<0.05$; Table 5). On 


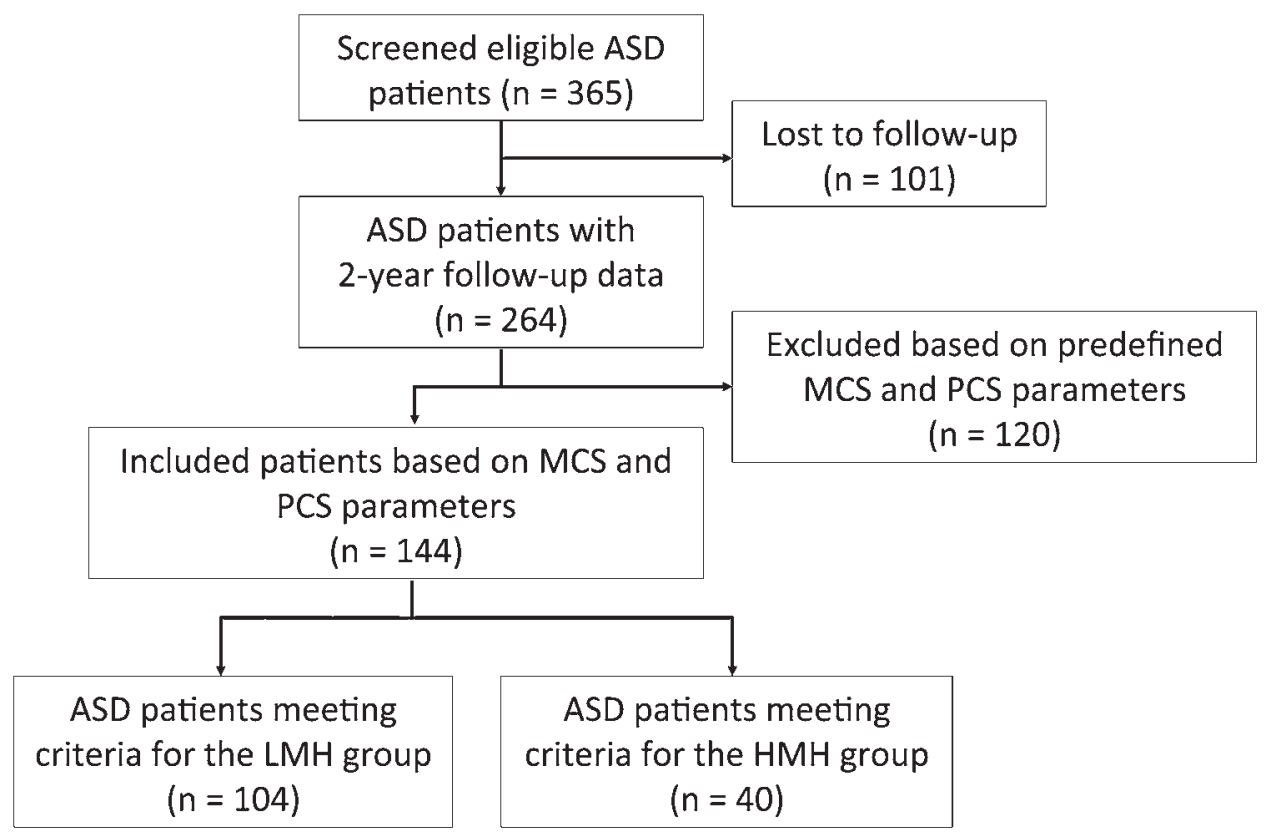

FIG. 1. Flow diagram of patients selected for each group.

multivariable logistic regression while controlling for covariables, having $\mathrm{LMH}$ was a significant independent predictor of a failure to reach an MCID for the PCS ( $p<0.05$; Table 6). At the 2-year postoperative follow-up, $14 \mathrm{LMH}$ patients (15.1\%) were categorized as HMH. Two LMH pa-

TABLE 1. Demographics and SRS-Schwab classification of the coronal curve deformity at baseline*

\begin{tabular}{|c|c|c|c|}
\hline Variable & LMH & $\mathrm{HMH}$ & $\mathrm{p}$ Value \\
\hline No. of patients & 104 & 40 & \\
\hline Age in yrs & $59.3 \pm 9.6$ & $52.8 \pm 18.3$ & 0.20 \\
\hline $\mathrm{F}: \mathrm{M}$ & $83: 21$ & $37: 3$ & 0.05 \\
\hline $\mathrm{BMI}$ in $\mathrm{kg} / \mathrm{m}^{2}$ & $29.2 \pm 5.9$ & $27 \pm 6.5$ & 0.02 \\
\hline $\mathrm{CCl}$ & $1.8 \pm 1.7$ & $1.3 \pm 1.4$ & 0.12 \\
\hline ASA physical status & $2.5 \pm 0.6$ & $2 \pm 0.7$ & $<0.01$ \\
\hline LOS in days & $8.4 \pm 5$ & $7.4 \pm 3.6$ & 0.08 \\
\hline OR time in min & $416.3 \pm 112.3$ & $371.2 \pm 149.6$ & 0.08 \\
\hline $\mathrm{EBL}$ in $\mathrm{ml}$ & $2043.3 \pm 1628$ & $1685.6 \pm 1453.7$ & 0.19 \\
\hline Decompressed & $72(69.2 \%)$ & $24(60.0 \%)$ & 0.30 \\
\hline \multicolumn{4}{|l|}{$\begin{array}{l}\text { Preop SRS-Schwab } \\
\text { coronal curve }\end{array}$} \\
\hline Type N & $34(33 \%)$ & $10(25 \%)$ & \multirow{4}{*}{0.35} \\
\hline Type T & $4(3.9 \%)$ & $3(7.5 \%)$ & \\
\hline Type L & $39(37.9 \%)$ & $12(30 \%)$ & \\
\hline Type D & $26(25.2 \%)$ & $15(37.5 \%)$ & \\
\hline
\end{tabular}

$\mathrm{CCl}=$ Charlson comorbidity index; LOS = length of hospital stay; OR = operating room.

* Values are expressed as the mean \pm standard deviation, unless indicated otherwise. $p<0.05$ was considered statistically significant; boldface type indicates statistical significance. tients (2.2\%) and $3 \mathrm{HMH}$ patients (7.7\%) transitioned to a PCS score $\geq 75$ th percentile for age- and sex-matched US norms $(\mathrm{p}<0.01$; Table 7$)$.

\section{Discussion}

Assessment of mental health parameters in ASD patients provides further insight into their prognostic outcomes from surgical intervention. The original hypothesis that patients with poor mental health may have worse 2 -year outcomes than those with good mental health was disproven. Our results indicated that both groups had significant improvements in the majority of HRQOL measurements compared with baseline. Patients with low MCS scores, compared to patients with higher MCS scores, can still benefit from reconstructive spine surgery. In this report, we also showed that patients with notable psychological distress significantly improved in most HRQOL outcome measures after spine deformity surgery. Patients should not be excluded as a surgical candidate because of poor preoperative MCS scores, but instead should receive a more comprehensive treatment approach.

A significant number of ASD patients have LMH. Analysis of our multiinstitutional database revealed a greater prevalence of $\mathrm{LMH}$ than $\mathrm{HMH}$ based on MCS scores $(28.5 \%$ vs $11.0 \%)$. In this report, patients with HMH were more likely to have clinically significant improvements in their physical health status than patients with $\mathrm{LMH}$, independent of baseline deformity type and baseline physical status. Patients with lower mental health scores tend to rate their health poorly and have frequent psychological distress as well as social and role disability because of emotional difficulties.9,26 This could limit improvements in physical self-care, bodily pain, and feelings of vitality. Patients with LMH were more likely to 
demonstrate clinically significant improvements in their mental health scores than the patients with low physical health and HMH. While this finding is probably attributable to a floor/ceiling effect, only $15.1 \%$ of patients in the LMH group met the requirements for the HMH category at the 2-year follow-up. These improvements may indicate the responsiveness of mental disability to surgical treatment, which is supported by the significantly higher MCS, SRS-22r mental, and SRS-22r satisfaction scores in the LMH patients. Any lack of improvement could be attributable to cognitive-behavioral disorders, such as anxiety and depression, which can result in higher rates of postoperative dissatisfaction and pain. Both patient groups had similar SRS-22r satisfaction and back and leg pain scores at baseline. However, at the 2-year follow-up, the HMH group demonstrated a greater reduction in back pain $(\mathrm{p}<$ 0.01 ), whereas LMH demonstrated greater improvements in SRS-22r satisfaction. The mechanisms involved in responding to emotional distress, such as catastrophizing and acceptance, were not captured in this study.

Patients in the LMH group had greater difficulties in improving their PCS scores. To help patients with lower mental health scores undergoing surgical treatments, projected difficulties in obtaining greater improvements should be discussed during the preoperative period. The preoperative workup for LMH patients should include a psychiatric evaluation, such as the Distress and Risk Assessment Method (DRAM), to determine if they have intrinsic depression or disease-related depression, which may benefit from antidepressant medication or cognitivebehavioral treatment. Patients with lumbar degenerative disease who improve their mental health function have been shown to have 1-year surgical outcomes similar to those in patients without mental health dysfunction..$^{10}$ The decrease in MCS scores in patients in the HMH group could be attributable to treatment complications or unmet patient expectations. Developing depressive symptoms after surgery have also been shown to have a negative impact on clinical outcomes. Mental health function can be associated with surgical outcomes and should be addressed preoperatively as well as during follow-up. Future studies should investigate the impact of concurrent treatment of mental health parameters on long-term clinical outcomes.

Medical comorbidities and employment status are also important determinants of a patient's mental health status. Adult spinal deformity patients with LMH had a significantly higher incidence of self-reported leg weakness, depression, hypertension, and neurological and psychiatric disease processes. Adult spinal deformity itself is a debilitating disease that has been shown to impact a patient's functional health in a manner similar to that in chronic comorbid conditions (arthritis, lung disease, diabetes, congestive health failure, and so forth).$^{17}$ When possible, comorbid parameters should be optimized before surgical intervention. Fu et al. demonstrated that ASD patients without comorbidities can have mental health scores similar to matched US norms. ${ }^{11}$ Particular preoperative social variables also emerged in patients with greater mental health distress; patients in the LMH group were more likely to be disabled, retired due to back pain, or unemployed.
TABLE 2. Preoperative comorbidities, symptom duration, and work status

\begin{tabular}{|c|c|c|c|}
\hline \multirow[b]{2}{*}{ Parameter } & \multicolumn{2}{|c|}{ No. $(\%)$} & \multirow{2}{*}{$\begin{array}{c}p \\
\text { Value }\end{array}$} \\
\hline & LMH & $\mathrm{HMH}$ & \\
\hline$\geq 1$ Comorbidity & $83(79.8)$ & $25(62.5)$ & 0.04 \\
\hline No. of comorbidities & & & 0.04 \\
\hline 0 & $21(20.2)$ & $15(37.5)$ & \\
\hline 1 & $21(20.2)$ & $10(25)$ & \\
\hline 2 & $20(19.2)$ & $7(17.5)$ & \\
\hline 3 & $17(16.3)$ & $6(15)$ & \\
\hline 4 & $12(11.5)$ & $2(5)$ & \\
\hline 5 & $6(5.8)$ & $0(0)$ & \\
\hline $6-9$ & $7(6.7)$ & $0(0)$ & \\
\hline \multicolumn{4}{|l|}{ Types } \\
\hline Bowel incontinence & $11(10.6)$ & $2(5)$ & 0.20 \\
\hline Numbness or tingling in legs & $55(52.9)$ & $18(45)$ & 0.12 \\
\hline Leg weakness & $62(59.6)$ & $12(30)$ & $<0.01$ \\
\hline Bladder incontinence & $21(20.2)$ & $6(15)$ & 0.31 \\
\hline Anemia & $10(9.6)$ & $3(7.5)$ & 0.69 \\
\hline Arthritis & $44(42.3)$ & $13(32.5)$ & 0.28 \\
\hline Deep venous thrombosis & $7(6.7)$ & $1(2.5)$ & 0.28 \\
\hline Cancer & $8(7.7)$ & $3(7.5)$ & 0.97 \\
\hline Depression & $45(43.3)$ & $1(2.5)$ & $<0.01$ \\
\hline Diabetes & $8(7.7)$ & $2(5)$ & 0.56 \\
\hline Heart disease & $11(10.6)$ & $1(2.5)$ & 0.08 \\
\hline Hypertension & $46(44.2)$ & $10(25)$ & 0.03 \\
\hline Kidney disease & $5(4.8)$ & $1(2.5)$ & 0.51 \\
\hline Liver disease & $1(1)$ & $0(0)$ & 0.42 \\
\hline Pulmonary disease & $6(5.8)$ & $4(10)$ & 0.39 \\
\hline Neurological disease & $9(8.7)$ & $0(0)$ & 0.01 \\
\hline Osteoporosis & $11(10.6)$ & $5(12.5)$ & 0.74 \\
\hline Peripheral vascular disease & $2(1.9)$ & $0(0)$ & 0.25 \\
\hline Psychiatric disease & $11(10.6)$ & $0(0)$ & 0.01 \\
\hline Gastric ulcer & $14(13.5)$ & $6(15)$ & 0.81 \\
\hline Smoker & $8(7.7)$ & $1(2.5)$ & 0.22 \\
\hline \multicolumn{4}{|l|}{ Duration of symptoms } \\
\hline Yrs w/ "spine problems" & $4.4 \pm 0.8$ & $4.3 \pm 0.9$ & 0.78 \\
\hline Yrs w/ back pain & $2.9 \pm 1.4$ & $3.1 \pm 1.5$ & 0.43 \\
\hline Yrs w/ leg pain & $2.3 \pm 1.8$ & $2.7 \pm 1.3$ & 0.03 \\
\hline Work status & & & $<0.01$ \\
\hline Disabled & $25(24)$ & $1(2.5)$ & \\
\hline Employed & $28(26.9)$ & $21(52.5)$ & \\
\hline Retired & $17(16.3)$ & $12(30)$ & \\
\hline Retired due to back pain & $11(10.6)$ & $0(0)$ & \\
\hline Unemployed & $13(12.5)$ & $3(7.5)$ & \\
\hline
\end{tabular}

* Boldface type indicates statistical significance.

This finding highlights the value of employment for mental health scores and the emphasis that should be placed on gathering information about any anticipated time off from work, financial burdens, and activity limitations during the patient's surgical evaluation. Moreover, addressing 
TABLE 3. Radiographic alignment measurements at baseline and the 2-year postoperative follow-up*

\begin{tabular}{|c|c|c|c|c|c|c|c|c|}
\hline \multirow{2}{*}{$\begin{array}{c}\text { Radiographic } \\
\text { Parameter }\end{array}$} & \multicolumn{3}{|c|}{ Preop } & \multicolumn{3}{|c|}{2 Yrs Postop } & \multicolumn{2}{|c|}{ Diff $p$ Value $\dagger$} \\
\hline & LMH & $\mathrm{HMH}$ & p Value & LMH & $\mathrm{HMH}$ & p Value & $\mathrm{LMH}$ & $\mathrm{HMH}$ \\
\hline $\mathrm{PT}\left({ }^{\circ}\right)$ & $25.3 \pm 11.2$ & $20.4 \pm 10.9$ & 0.06 & $22.7 \pm 9.8$ & $18.6 \pm 10.6$ & 0.03 & 0.11 & 0.21 \\
\hline $\mathrm{PI}-\mathrm{LL}\left({ }^{\circ}\right)$ & $18.1 \pm 21.1$ & $9.5 \pm 16.2$ & 0.02 & $5.9 \pm 14.2$ & $-1.3 \pm 11.8$ & $<0.01$ & $<0.01$ & $<0.01$ \\
\hline $\mathrm{TK}\left({ }^{\circ}\right)$ & $34.2 \pm 19$ & $36.1 \pm 17.2$ & 0.43 & $48.7 \pm 18.4$ & $48.7 \pm 15.5$ & 0.66 & $<0.01$ & $<0.01$ \\
\hline SVA (mm) & $73.8 \pm 73.2$ & $50.3 \pm 74$ & 0.04 & $36.8 \pm 52.8$ & $18.2 \pm 51.4$ & 0.03 & $<0.01$ & 0.03 \\
\hline \multicolumn{9}{|l|}{ Cobb angle $\left({ }^{\circ}\right) \ddagger$} \\
\hline UT & $27.7 \pm 10.2$ & $24.1 \pm 11.3$ & 0.09 & $16.6 \pm 10.6$ & $15.4 \pm 6.3$ & 0.89 & $<0.01$ & 0.01 \\
\hline $\mathrm{TH}$ & $40 \pm 21.5$ & $42.2 \pm 16.7$ & 0.55 & $23.7 \pm 20.8$ & $21.7 \pm 13.1$ & 0.69 & $<0.01$ & $<0.01$ \\
\hline TL & $42.3 \pm 23.3$ & $40 \pm 15$ & 0.88 & $20.8 \pm 18.6$ & $21.2 \pm 11.6$ & 0.32 & $<0.01$ & $<0.01$ \\
\hline LL & $32.6 \pm 14.9$ & $34.6 \pm 18.2$ & 0.79 & $16.6 \pm 12.1$ & $15.3 \pm 12.3$ & 0.57 & $<0.01$ & $<0.01$ \\
\hline
\end{tabular}

* Boldface type indicates statistical significance.

$\dagger$ Two-year difference (Diff), where preoperative and 2-year postoperative values in the same group were compared for statistical significance.

$\ddagger$ Cobb angles classified as upper thoracic (UT), thoracic (TH), thoracolumbar (TL), and lower lumbar (LL) based on the curve apex.

TABLE 4. Health-related QOL measurements at baseline and the 2-year postoperative follow-up*

\begin{tabular}{|c|c|c|c|c|c|c|c|c|}
\hline \multirow[b]{2}{*}{ Measure } & \multicolumn{3}{|c|}{ Preop } & \multicolumn{3}{|c|}{2 Yrs Postop } & \multicolumn{2}{|c|}{ Diff $p$ Value } \\
\hline & LMH & $\mathrm{HMH}$ & p Value & LMH & $\mathrm{HMH}$ & $p$ Value & LMH & $\mathrm{HMH}$ \\
\hline ODI & $55.4 \pm 14.8$ & $34 \pm 12.2$ & $<0.01$ & $38 \pm 21$ & $16.1 \pm 16.4$ & $<0.01$ & $<0.01$ & $<0.01$ \\
\hline PCS & $29 \pm 6.2$ & $31.3 \pm 7.4$ & 0.06 & $35.4 \pm 9.8$ & $45.5 \pm 10.4$ & $<0.01$ & $<0.01$ & $<0.01$ \\
\hline MCS & $32.9 \pm 8.6$ & $62.7 \pm 4.3$ & $<0.01$ & $43.7 \pm 13.8$ & $58 \pm 8$ & $<0.01$ & $<0.01$ & 0.01 \\
\hline \multicolumn{9}{|l|}{ SRS-22r } \\
\hline Activity & $2.3 \pm 0.7$ & $3.5 \pm 0.5$ & $<0.01$ & $3 \pm 1$ & $4.2 \pm 0.8$ & $<0.01$ & $<0.01$ & $<0.01$ \\
\hline Pain & $1.9 \pm 0.6$ & $2.9 \pm 0.6$ & $<0.01$ & $2.9 \pm 1.2$ & $4 \pm 0.9$ & $<0.01$ & $<0.01$ & $<0.01$ \\
\hline Self-image & $2 \pm 0.6$ & $2.9 \pm 0.5$ & $<0.01$ & $3.3 \pm 0.9$ & $4.3 \pm 0.7$ & 0.18 & $<0.01$ & $<0.01$ \\
\hline Mental health & $2.7 \pm 0.7$ & $4.4 \pm 0.4$ & $<0.01$ & $3.4 \pm 0.9$ & $4.5 \pm 0.5$ & $<0.01$ & $<0.01$ & 0.08 \\
\hline Satisfaction & $2.5 \pm 1$ & $2.5 \pm 1$ & 0.48 & $4 \pm 1$ & $4.5 \pm 0.7$ & 0.05 & $<0.01$ & $<0.01$ \\
\hline Total & $2.3 \pm 0.5$ & $3.3 \pm 0.3$ & $<0.01$ & $3.2 \pm 0.9$ & $4.3 \pm 0.5$ & $<0.01$ & $<0.01$ & $<0.01$ \\
\hline \multicolumn{9}{|l|}{ NRS } \\
\hline Back pain & $7.9 \pm 2$ & $7.3 \pm 1.9$ & 0.13 & $4.6 \pm 3.3$ & $2.3 \pm 2.6$ & 0.07 & $<0.01$ & $<0.01$ \\
\hline Leg pain & $5.4 \pm 3.2$ & $3.7 \pm 3.3$ & 0.28 & $3.4 \pm 3.1$ & $1.5 \pm 2.3$ & 0.06 & $<0.01$ & $<0.01$ \\
\hline
\end{tabular}

* Boldface type indicates statistical significance.

TABLE 5. Patients who reached an MCID at the 2-year postoperative follow-up*

\begin{tabular}{lcrr}
\hline \multicolumn{1}{c}{ Measure } & LMH & HMH & p Value \\
\hline ODI & $50 / 102(49 \%)$ & $25 / 40(62.5 \%)$ & 0.15 \\
\hline PCS & $46 / 93(49.5 \%)$ & $31 / 39(79.5 \%)$ & $<0.01$ \\
\hline SRS-22r & & & \\
\hline Activity & $67 / 101(66.3 \%)$ & $33 / 39(84.6 \%)$ & 0.03 \\
\hline Pain & $65 / 101(64.4 \%)$ & $29 / 39(74.4 \%)$ & 0.25 \\
\hline Self-image & $74 / 101(73.3 \%)$ & $29 / 39(74.4 \%)$ & 0.90 \\
\hline Mental health & $63 / 101(62.4 \%)$ & $9 / 39(23.1 \%)$ & $<0.01$ \\
\hline
\end{tabular}

* Denominator was based on the number of patients eligible for improvements in the MCID.

† Boldface type indicates statistical significance. these comorbidities in ASD patients may help to improve their overall mental health status.

The duration of symptoms before surgery can also have a negative impact on functional outcomes. ${ }^{18}$ In our study, symptom duration in the 2 groups was similar, except that the HMH group had more years of leg pain. To our knowledge, this is the first study investigating the role of mental health dysfunction as indicated by the SF-36 in reconstructive spine surgery for ASD patients. Previous studies investigating the impact of mental health in spine surgery patients have used various mental health scales and have been limited to lumbar degenerative spine surgeries. Several studies have shown that preoperative health dysfunction has a significant negative impact on clinical outcomes. , $10,23,24$ Falavigna et al. prospectively analyzed the responsiveness of depression and its influence on the outcomes of 91 patients undergoing surgery for lumbar degenerative diseases. ${ }^{10}$ At the 1-year follow-up, the authors 
TABLE 6. Multivariable binary logistic regression analysis of the likelihood of reaching an MCID for the listed HRQOL measures*

\begin{tabular}{lcc}
\hline MCID & OR $(95 \% \mathrm{Cl})$ & p Value \\
\hline ODI & $0.562(0.190-1.663)$ & 0.298 \\
\hline PCS & $0.313(0.107-0.919)$ & 0.035 \\
\hline SRS-22r & & \\
\hline Activity & $0.405(0.105-1.565)$ & 0.19 \\
\hline Pain & $0.658(0.203-2.132)$ & 0.486 \\
\hline Self-image & $0.961(0.278-3.318)$ & 0.949 \\
\hline Mental health & $0.341(0.058-2.008)$ & 0.234 \\
\hline
\end{tabular}

* LMH vs HMH (HMH reference). Covariates included age, sex, BMI, ASA physical status, $\mathrm{CCI}$, SRS-Schwab coronal class, preoperative maximum Cobb, SVA, PT, PI-LL, and preoperative HRQOL for the outcome (for example, preoperative ODI for ODI MCID model). Boldface type indicates statistical significance.

found that patients with continued depression were associated with worse functional outcomes and that patients who recovered from their depression had outcomes similar to those in patients without depression. Sinikallio et al. prospectively evaluated the predictive value of preoperative and 3-month postoperative depressive symptoms on 1-year outcomes after decompressive surgery in 102 patients with symptomatic lumbar spinal stenosis. ${ }^{23}$ These authors found that a higher depressive burden (assessed by the 21item Beck Depression Inventory) was independently associated with greater disability, pain and symptom severity, and limited walking capacity at the 1-year follow-up. They also found that satisfaction was worse in patients who experienced depression postoperatively. Trief et al. prospectively analyzed 102 chronic back pain patients who completed measures of distress (DRAM, anxiety, depression, and hostility) before surgery and measures of pain change, function, and employment status 1 year after surgery. ${ }^{24}$ These authors found that preoperative anxiety and depression have a significant impact on pain change ratings, functional measure outcomes (Dallas Pain Questionnaire), and work status. Derby et al. retrospectively analyzed SF36 scores in 57 patients undergoing lumbar spine surgery. ${ }^{9}$ They found that patients with MCS scores $<40$ exhibited substantially worse clinical outcomes. The study population had mean MCS and PCS values similar to those in our study; however, the authors did not observe similar significant postoperative improvement. Their sample size was small, and differences in the patient population, age, and reconstructive approaches may have contributed to the different results observed.

Two retrospective studies found no correlation between mental health parameters and clinical outcome assessments. Hobby et al. analyzed 66 patients undergoing lumbar discectomy $y^{13}$ and found that disability correlated with psychological disturbances (DRAM) preoperatively but did not impact clinical outcome. In fact, they demonstrated an association between mental health improvement and disability. Asher et al. analyzed 83 patients undergoing minimally invasive lumbar surgery and found no relationship between preoperative general mental health and postoperative clinical outcomes (visual analog scale, ODI, or PCS) in patients with mental health scores comparable to the population mean. ${ }^{1}$

The use of a prospective database with clinical data that were collected through a uniform process from 11 institutions is a major strength of this study, although the study is retrospective and nonrandomized. Groups were found to have similar demographics and coronal Cobb values, and thus confounding variables were limited. Information on the type of self-reported psychiatric distress, anxiety or depression levels and their respective treatment regimens, and emotional mechanisms of responsiveness to surgery were unavailable. The definition of LMH was limited to the population with poor MCS scores $(\leq 25$ th percentile for age- and sex-matched norms). Self-reported measures may have led to an overestimation of the impact of mental health parameters and poor physical functioning, and the addition of objective assessments of physical function may reduce this bias. We used self-reported HRQOL outcomes, namely the SF-36, to assess their relationships. While the use of DRAM has also been advocated when assessing psychological distress, ${ }^{8}$ the mental health component of the SRS-22r has been shown to be an adequate surrogate for DRAM. ${ }^{12}$ Other questionnaires used to diagnose anxiety or depression were not available in our database. We were unable to select only those patients who were eligible for significant MCID improvements in MCS scores in the HMH group given the limited number of patients meeting these criteria; therefore, MCID MCS scores were not calculated.

\section{Conclusions}

While patients with poor mental and physical health,

TABLE 7. Distribution patterns in 2-year postoperative MCS and PCS changes*

\begin{tabular}{|c|c|c|c|c|c|c|c|}
\hline \multirow[b]{2}{*}{ Preop MCS } & \multirow[b]{2}{*}{$\begin{array}{c}\text { Initial Sample } \\
\text { Size }\end{array}$} & \multicolumn{3}{|c|}{ 2-Yr Postop MCS } & \multicolumn{3}{|c|}{ 2-Yr Postop PCS } \\
\hline & & $\begin{array}{c}\leq 25 \text { th } \\
\text { Percentile }\end{array}$ & $\begin{array}{l}\text { 26th-74th } \\
\text { Percentile }\end{array}$ & $\begin{array}{c}\geq 75 \text { th } \\
\text { Percentile }\end{array}$ & $\begin{array}{c}\leq 25 \text { th } \\
\text { Percentile }\end{array}$ & $\begin{array}{l}\text { 26th-74th } \\
\text { Percentile }\end{array}$ & $\begin{array}{c}\geq 75 \text { th } \\
\text { Percentile }\end{array}$ \\
\hline$\leq 25$ th percentile $(\mathrm{LMH})$ & $93(100 \%)$ & $46(49.5 \%)$ & $33(35.5 \%)$ & $14(15.1 \%)$ & $67(72 \%)$ & $24(25.8 \%)$ & $2(2.2 \%)$ \\
\hline 26th-74th percentile & $50(100 \%)$ & $9(18 \%)$ & $26(52 \%)$ & $15(30 \%)$ & $22(44 \%)$ & $25(50 \%)$ & $3(6 \%)$ \\
\hline$\geq 75$ th percentile $(\mathrm{HMH})$ & $39(100 \%)$ & $3(7.7 \%)$ & $11(28.2 \%)$ & $25(64.1 \%)$ & $11(28.2 \%)$ & $25(64.1 \%)$ & $3(7.7 \%)$ \\
\hline
\end{tabular}


according to their MCS and PCS scores, have a higher rate of medical comorbidities and unemployment rates, they still demonstrate significant improvements in HRQOL measurements postoperatively. Both LMH and HMH patient groups demonstrated similar improvements in most HRQOL domains, except that the LMH patients had difficulties in obtaining improvements in the PCS domain.

\section{References}

1. Asher R, Mason AE, Weiner J, Fessler RG: The relationship between preoperative general mental health and postoperative quality of life in minimally invasive lumbar spine surgery. Neurosurgery 76:672-679, 2015

2. Baldus C, Bridwell KH, Harrast J, Edwards C II, Glassman S, Horton W, et al: Age-gender matched comparison of SRS instrument scores between adult deformity and normal adults: are all SRS domains disease specific? Spine (Phila Pa 1976) 33:2214-2218, 2008

3. Blondel B, Schwab F, Ungar B, Smith J, Bridwell K, Glassman S, et al: Impact of magnitude and percentage of global sagittal plane correction on health-related quality of life at 2-years follow-up. Neurosurgery 71:341-348, 2012

4. Carreon LY, Sanders JO, Diab M, Sucato DJ, Sturm PF, Glassman SD: The minimum clinically important difference in Scoliosis Research Society-22 Appearance, Activity, and Pain domains after surgical correction of adolescent idiopathic scoliosis. Spine (Phila Pa 1976) 35:2079-2083, 2010

5. Champain S, Benchikh K, Nogier A, Mazel C, Guise JD, Skalli W: Validation of new clinical quantitative analysis software applicable in spine orthopaedic studies. Eur Spine J 15:982-991, 2006

6. Charlson M, Szatrowski TP, Peterson J, Gold J: Validation of a combined comorbidity index. J Clin Epidemiol 47:12451251,1994

7. Copay AG, Glassman SD, Subach BR, Berven S, Schuler TC, Carreon LY: Minimum clinically important difference in lumbar spine surgery patients: a choice of methods using the Oswestry Disability Index, Medical Outcomes Study questionnaire Short Form 36, and pain scales. Spine J 8:968-974, 2008

8. Daubs MD, Patel AA, Willick SE, Kendall RW, Hansen P, Petron DJ, et al: Clinical impression versus standardized questionnaire: the spinal surgeon's ability to assess psychological distress. J Bone Joint Surg Am 92:2878-2883, 2010

9. Derby R, Lettice JJ, Kula TA, Lee SH, Seo KS, Kim BJ: Single-level lumbar fusion in chronic discogenic low-back pain: psychological and emotional status as a predictor of outcome measured using the 36-Item Short Form. J Neurosurg Spine 3:255-261, 2005

10. Falavigna A, Righesso O, Teles AR, Conzati LP, Bossardi JB, da Silva PG, et al: Responsiveness of depression and its influence on surgical outcomes of lumbar degenerative diseases. Eur J Orthop Surg Traumatol 25 (Suppl 1):S35-S41, 2015

11. Fu KMG, Bess RS, Schwab FJ, Shaffrey CI, Lafage V, Smith JS, et al: Health impact comparison of different disease states and population norms to adult spinal deformity (ASD): a call for medical attention. Spine J 12 (9 Suppl):S2, 2012

12. Fu KMG, Burton DC, Lai SM, Akbarnia BA, Ames CP, Bess $S$, et al: The association between DRAM and the SRS 22r: can we substitute the SRS 22r for the DRAM for assessing psychological distress? Presented at the Congress of Neurological Surgeons 2011 Annual Meeting, Washington, DC (Poster) (http://2011.cns.org/posterbrowser.aspx) [Accessed June 15, 2016]

13. Hobby JL, Lutchman LN, Powell JM, Sharp DJ: The distress and risk assessment method (DRAM). J Bone Joint Surg Br 83:19-21, 2001
14. Hu SS, Berven SH: Preparing the adult deformity patient for spinal surgery. Spine (Phila Pa 1976) 31 (19 Suppl):S126S131, 2006

15. Menendez ME, Neuhaus V, Bot AG, Ring D, Cha TD: Psychiatric disorders and major spine surgery: epidemiology and perioperative outcomes. Spine (Phila Pa 1976) 39:E111E122, 2014

16. O’Brien MF, Kuklo TR, Blanke KM, Lenke LG (eds): Spinal Deformity Study Group Radiographic Measurement Manual. Memphis, TN: Medtronic Sofamor Danek, 2005

17. Pellisé F, Vila-Casademunt A, Ferrer M, Domingo-Sàbat M, Bagó J, Pérez-Grueso FJ, et al: Impact on health related quality of life of adult spinal deformity (ASD) compared with other chronic conditions. Eur Spine J 24:3-11, 2015

18. Radcliff KE, Rihn J, Hilibrand A, Dilorio T, Tosteson T, Lurie JD, et al: Does the duration of symptoms in patients with spinal stenosis and degenerative spondylolisthesis affect outcomes?: analysis of the Spine Outcomes Research Trial. Spine (Phila Pa 1976) 36:2197-2210, 2011

19. Rillardon L, Levassor N, Guigui P, Wodecki P, Cardinne L, Templier A, et al: [Validation of a tool to measure pelvic and spinal parameters of sagittal balance.] Rev Chir Orthop Repar Appar Mot 89:218-227, 2003 (Fr)

20. Rose MS, Koshman ML, Spreng S, Sheldon R: Statistical issues encountered in the comparison of health-related quality of life in diseased patients to published general population norms: problems and solutions. J Clin Epidemiol 52:405412, 1999

21. Schwab F, Ungar B, Blondel B, Buchowski J, Coe J, Deinlein D, et al: Scoliosis Research Society-Schwab adult spinal deformity classification: a validation study. Spine (Phila Pa 1976) 37:1077-1082, 2012

22. Searle SD, Mitnitski A, Gahbauer EA, Gill TM, Rockwood $\mathrm{K}$ : A standard procedure for creating a frailty index. BMC Geriatr 8:24, 2008

23. Sinikallio S, Aalto T, Airaksinen O, Herno A, Kröger H, Viinamäki H: Depressive burden in the preoperative and early recovery phase predicts poorer surgery outcome among lumbar spinal stenosis patients: a one-year prospective follow-up study. Spine (Phila Pa 1976) 34:2573-2578, 2009

24. Trief PM, Grant W, Fredrickson B: A prospective study of psychological predictors of lumbar surgery outcome. Spine (Phila Pa 1976) 25:2616-2621, 2000

25. von Elm E, Altman DG, Egger M, Pocock SJ, Gøtzsche PC, Vandenbroucke JP: The Strengthening the Reporting of Observational Studies in Epidemiology (STROBE) statement: guidelines for reporting observational studies. Epidemiology 18:800-804, 2007

26. Ware JE Jr: SF-36 health survey update. Spine (Phila Pa 1976) 25:3130-3139, 2000

27. Ware JE Jr: U.S. population norms. SF-36.org. (http://www. sf-36.org/research/sf98norms.pdf) [Accessed June 15, 2016]

28. Young AK, Young BK, Riley LH III, Skolasky RL: Assessment of presurgical psychological screening in patients undergoing spine surgery: use and clinical impact. J Spinal Disord Tech 27:76-79, 2014

\section{Disclosures}

Funding for the International Spine Study Group Foundation, through which this study was conducted, is supported through research grants from DePuy Spine and individual donations. Dr. Shaffrey has been a consultant for Biomet, Medtronic, and Nuvasive; has owned stock in Nuvasive; has held patents with Biomet and Medtronic; has received support from the NIH and the Department of Defense for non-study-related clinical or research effort; and has received clinical or research support from the International Spine Study Group (ISSG) for the study described. Dr. Burton has held a patent with and has received clinical or 
research support for the study described from DePuy. Dr. Schwab has owned stock in Nemairs Inc.; has been a consultant for and has had speaking/teaching arrangements with Zimmer-Biomet, K2M, Nuvasive, Medicrea, and MSD; and has received support from SRS, AOSpine, and DePuy Spine Synthesis (paid through ISSG). Dr. Smith has been a consultant for and has received royalties from Zimmer-Biomet; has been a consultant for Nuvasive and Cerapedics; has received clinical or research support from DePuy Synthes both for the study described and for another unrelated study; has received fellowship funding from NREF and AOSpine; and has received honorarium from K2M. Dr. Hostin has been a consultant for and has received non-study-related support from DePuy; and has received non-study-related support from Nuvasive, Seeger, K2M, and DJO. Dr. Ames has been a consultant for DePuy, Medtronic, and Stryker; has held a patent with Fish \& Richardson, PC; and has received royalties from Biomet Spine and Stryker. Dr. Mundis has been a consultant for Nuvasive. K2M, Misonix, and Ellipse and has held a patent with K2M. Dr. Lafage has held stock in Nemaris Inc.; has been a consultant for Nuvasive; has had speaking/teaching arrangements with DePuy Synthes, Nuvasive, Medicrea, Nemaris Inc.; and has received non-study-related support from SRS, the NIH, and DePuy (paid through ISSGF). Dr. Gum has been a consultant for Medtronic, DePuy, Alphatec, Stryker, LifeSpine, Acuity, and PAKmed; has received honorarium from MiMedx and Pacira Pharmaceuticals; has received a grant for travel from the Fischer Owen Fund; has received research support from Integra, Intellirod Spine Inc., International Spine Study Group, with funds to the institution only; and has received database support from Nuvasive. Dr. Hart has been a consultant for DePuy Synthes and
Globus, has held a patent with Oregon Health \& Science University, has received royalties from Seaspine and DePuy Synthes, and has received grant support from ISSG. Dr. Bess has been a consultant for K2M and Allosource, has held patents with K2M and Innovasis, has received study-related clinical or research support from Nuvasive, K2M, Medtronic, DePuy Synthes, and Stryker. Dr. Protopsaltis has been a consultant for Medicrea International, has received study-related clinical or research support from Zimmer Spine, and has been part of the speaker's bureau at Innovasis.

\section{Author Contributions}

Conception and design: Scheer, Ames, Bakhsheshian. Acquisition of data: all authors. Analysis and interpretation of data: Bakhsheshian, Scheer, Lafage, Ames. Drafting the article: Bakhsheshian. Critically revising the article: Bakhsheshian, Scheer, Gum, Hostin, Lafage, Bess, Protopsaltis, Burton, Hart, Mundis, Shaffrey, Schwab, Smith, Ames. Reviewed submitted version of manuscript: all authors. Approved the final version of the manuscript on behalf of all authors: Bakhsheshian. Statistical analysis: Bakhsheshian, Scheer, Keefe. Administrative/ technical/material support: Bakhsheshian, Scheer, Keefe. Study supervision: Scheer, Ames.

\section{Correspondence}

Joshua Bakhsheshian, Department of Neurological Surgery, Keck School of Medicine, University of Southern California, 1200 North State St., Ste. 3300, Los Angeles, CA 90033. email: joshuabakh@gmail.com. 